\title{
LAND USE AND MANAGEMENT MAP PREPARATION PROCEDURE FOR THE LANDSLIDE HAZARD ZONATION MAPPING PROJECT IN SRI LANKA
}

\author{
RMAK Rathnayake \\ National Building Research Organization, Colombo 05
}

Seven districts out of 25 in Sri Lanka are prone to landslide. National Building Research Organization (NBRO) is being carried out Landslide Hazard Zonation Mapping Project (LHMP) for these districts from 1990. For the purpose of this six maps i.e. Land form map, Slope category map, Bedrock geology, Hydrology, Landslide \& Colluvium and Land use \& Management maps were used.

In the case of the land use and management legend development all national and international standards and norms were evaluated and those applicable for the hazard zonation exercise were adopted.

The legends used by various organizations connected with land use planning, such as forest land use mapping project, Land use Policy Planning Division of the Survey Department, Land use Division of the Irrigation Department and the Integrated Rural Development Project were scrutinized and evaluated as to their applicability for use in the legend development process.

It was observed, after the above exercise was completed, that the existing legends used by these organizations lacked the required details and direction to accommodate the depth and emphasis to be placed on the management related stability parameters of land use categories that are important in state of nature criteria to be mapped for landslide hazard assessment. Therefore, a special purpose stability oriented land use \& management legend should be evolved for this kind of special exercise.

In order to develop the land use \& management legend for LHMP, different management categories prevalent within the project area that could be identified to the scale of 1:10,000 and demarcated though systematic air photo interpretations were identified.

The different management based land use categories and land use map units of the evolved legend were demarcated on transparent overlays affixed to the Air Photos (APs) being interpreted. Areas with doubtful land uses were marked with question marks for verification in the field. APs to the scale of $1: 10,000$ in semi gloss papers were used for interpretations.

Four different stages an be involved in the map preparation which are transfer of land use boundaries to $1: 10,000 \mathrm{ABMP}$ maps, intermediate base overlay maps, updating using existing maps and field checking \& finalisation. 